COMMENT

\title{
Biobanking in radiotherapy trials - a challenge to the clinical research community
}

Duncan C. Gilbert and Valerie Speirs

\section{Standfirst}

Precision oncology is predicated on information derived from high-quality tissue samples. [Au: Edits for brevity OK?] Despite almost half of all patients with cancer receiving radiotherapy, samples from these patients are much less commonly available for use in biomarker studies. [Au: Is this what you meant?] Biobanks that include material from radiotherapy studies do exist; the challenge is increasing their visibility and accessibility to researchers to continue our efforts to improve outcomes for our patients.

The move towards personalized medicine for precision oncology depends on the identification of biomarkers of sensitivity and resistance, not only in tumours but also in non-malignant tissues. This requirement is, in turn, dependent on sufficiently large collections of high-quality samples from patients that can be linked to clinical outcomes data. Genomic and transcriptomic data deposited in freely accessible databases has been massively helpful to translational research, thus informing our understanding of cancer biology. Nevertheless, access to human tissue that is surplus to diagnostic and other clinical needs is also required, aligned with well annotated data on the natural history of the disease and/or treatment responses. Accordingly, biobanks have been established, and biobanking is now a well-established biomedical discipline. In recognition of the value of biobanking, the National Cancer Research Institute (NCRI) established the Confederation of Cancer Biobanks (CCB), [Au: Reference 1 has been moved to a 'Related links' section and hyperlink. Please ensure the other references renumbered accordingly.] with the aim of improving coordination between existing collections, raising awareness of these resources and sharing best practices. Subsequently, the CCB was absorbed into another NCRI workstream, the Cellular Molecular Pathology (CMPath) initiative. When first established, cancer biobanks tended to provide only samples of primary tumours, which generally yield surplus tissue even after pathologists take what is needed for diagnostic purposes. In the early days of biobanking, such samples were sufficient to meet the needs of researchers. Nowadays, translational research studies necessitate the use of a wide variety of pre-treatment and 
post-treatment samples, including metastatic tissues, allied with comprehensive pathology, treatment and outcomes data. [Au: Minor edits to this section for brevity OK?]

Almost half of all patients with cancer receive radiotherapy, but samples from these patients are much less commonly available for translational research. [Au:OK?] Modern radiotherapy techniques involve complex patient immobilization and image guidance processes for optimization of tumour dosing and fractionation schedules and maximal avoidance of non-malignant tissues. What is currently missing from these algorithms, however, is an appreciation of individual patients' tumour and non-malignant tissue sensitivity to radiation that would enable further improvement in the therapeutic ratio. Ideally, relevant samples would be collected in the context of clinical trials, in which patient, tumour and treatment characteristics (including highly annotated outcome data) are well controlled and documented, then stored in biobanks indefinitely. Notwithstanding, numerous subsequent issues must be addressed. [Au:OK?] For example, how do these biobanks indicate access and usage? [Au: I am not sure what you mean by 'indicate' in this context. Please clarify.] Who can access samples? Is access restricted to the trial investigators, particular research groups [Au: 'cartels' could have derogatory connotations. Edits OK? Please edit as you see fit.] or open to all? How is accessibility regulated? How are applications assessed as successful, unsuccessful [Au:OK?] or ranked in importance? Where are the national databases of biobanks and their stock lists?

In the UK, all tissue collected and stored in a Human Tissue Authority (HTA)-approved biobank must be registered with the UK Clinical Research Collaboration Tissue Directory and Coordination Centre, who highlight such biobanks on their website. [Au: Reference $\mathbf{2}$ has also been hyperlinked and added to the 'Related links' section] This website currently lists 12 biobanks of tissues from radiotherapy-related clinical studies (TABLE 1), all with email addresses and other contact details; however, few of the questions posed above are fully answerable, and the level of access (local, collaborative or open) and the process of obtaining samples are unclear. These issues are not unique to these biobanks; improvements in the discoverability of biobanks and access to their content are required more generally ${ }^{3}$. [Au:OK?] Other relevant tissue collections might exist (for example, samples collected prior to the HTA requirements), but are likely to be inaccessible to the research community. [Au:OK?]

Outside of the UK, the Genetic Pathways for the Prediction of the Effects of Irradiation (GENEPI) project was established nearly 20 years ago to identify molecular and genetic biomarkers of radiation response ${ }^{4}$. Tissues collected in GENEPI biobank included dermal fibroblasts, whole blood, lymphocytes, plasma and lymphoblastoid cell lines from patients with tumour demonstrating hypersensitivity to radiation. [Au: Is this what you meant? Perhaps an alternative it 'with excellent clinical responses to radiotherapy?] Subsequently, this biobank evolved into the GENEPI II European 
Normal and Tumour Tissue Bank and Data Base (GENEPI-ENTB 2), [Au:OK?] which consolidated multiple small, private sample collections throughout the European Union (EU) into a 'virtual EU tissue bank' with a common set of guidelines and standard operating procedures linked to a central database that could be accessed [Au: openly?] for data input and mining ${ }^{5}$. During the lifetime of this EU-wide project (September 2006 to February 2011), 12,120 samples from 5,844 patients treated with radiotherapy and 960 volunteers without cancer [Au:OK?] were collected and documented, presenting a vast research resource.

The value of translational studies in radiotherapy is exemplified by RAPPER (Radiogenomics: Assessment of Polymorphisms for Predicting the Effects of Radiotherapy), a collaborative study led by the UK clinical oncology community to determine whether common genetic variants associated with the risk of radiation toxicities could be identified and used in combination with non-genetic risk factors to personalize radiotherapy ${ }^{6}$. [Au: Edits OK?] By linking germline genotypes with high-quality outcomes data, [Au:OK?] this study increased the understanding of the genetics of radiation toxicities, spawning high-profile genetic epidemiology and genome-wide association studies ${ }^{7,8}$. RAPPER illustrates what is possible in translational research when researchers with a shared vision on improving patient outcomes come together and should be used as an exemplar to drive progress in this area. [Аu:ОK?]

Thus, biobanks that hold material from radiotherapy studies clearly exist. The challenge is increasing their visibility and accessibility to researchers. Tissue samples are a valuable resource, and patients willingly consent to the use of excess tissue in research but have little or no say over the scientific or clinical application of the samples they have generously provided. They do, however, have a right to know what is being done with them, that the samples are valued, and that they will be stored and used according to high-quality good clinical laboratory practice (GCLP)-validated protocols. A key message is that "Biobanks should not be Safety Deposit boxes accessed by the privileged few but more like open access accounts with stakeholders and others having easy access to deposit and withdraw". [Au: Is this a direct quote from another report? If so, please provide a reference.]

Widespread biobanking tissue samples from radiotherapy studies will provide an essential resource for the continuous efforts to improve outcomes for our patients. Examples of good practice exist - it is up to the clinical research community with the continued support of funders to deliver on this promise.

Duncan C. Gilbert ${ }^{1+}$ and Valerie Speirs ${ }^{2+}$

${ }^{1}$ MRC Clinical Trials Unit, University College London, London, UK. 
${ }^{2}$ Institute of Medical Sciences, School of Medicine, Medical Sciences and Nutrition, University of Aberdeen, Aberdeen, Scotland, UK. [Au: Edit OK?]

†e-mail: duncan.gilbert@ucl.ac.uk; valerie.speirs@abdn.ac.uk

3 Hall, A., Speirs, V., Hair, J., Thomas, G. \& Peach, J. in The Bulletin of the Royal College of Pathologists 94-96 (2019).

4 Baumann, M., Hölscher, T. \& Begg, A. C. Towards genetic prediction of radiation responses: ESTRO's GENEPI project. Radiotherapy and oncology : journal of the European Society for Therapeutic Radiology and Oncology 69, 121-125, doi:10.1016/j.radonc.2003.08.006 (2003).

5 De Ruysscher, D. et al. First report on the patient database for the identification of the genetic pathways involved in patients over-reacting to radiotherapy: GENEPI-II. Radiotherapy and oncology : journal of the European Society for Therapeutic Radiology and Oncology 97, 36-39, doi:10.1016/j.radonc.2010.03.012 (2010).

6 Burnet, N. G., Barnett, G. C., Summersgill, H. R., Dunning, A. M. \& West, C. M. L. RAPPER - A Success Story for Collaborative Translational Radiotherapy Research. Clinical oncology (Royal College of Radiologists (Great Britain)) 31, 416-419, doi:10.1016/j.clon.2019.04.013 (2019).

7 Barnett, G. C. et al. Independent validation of genes and polymorphisms reported to be associated with radiation toxicity: a prospective analysis study. The Lancet. Oncology 13, 6577, doi:10.1016/s1470-2045(11)70302-3 (2012).

8 Fachal, L. et al. A three-stage genome-wide association study identifies a susceptibility locus for late radiotherapy toxicity at 2q24.1. Nat Genet 46, 891-894, doi:10.1038/ng.3020 (2014).

\section{Acknowledgements}

The authors wish to thank Prof. Nicola Curtin for initiating and contributing to this work, Dr Tim Ward and $\mathrm{Dr}$ George Higginbotham for their input, and the National Cancer Research Institute (NCRI) Clinical and Translational Radiotherapy Research Working Group (CTRad) and Cellular Molecular Pathology Initiative (CMPath) workstreams for making this work possible. [Au:OK?]

\section{Competing interests}

The authors declare no competing interests. [Au:OK?]

Related links

Confederation of Cancer Biobanks: https://cmpath.ncri.org.uk/ccb/

UK Clinical Research Collaboration Tissue Directory and Coordination Centre: https://biobankinguk.org/ 
Table 1 | Example biobanks of samples collected after radiotherapy [Au: Shortened heading OK?

Information about these biobanks being registered, etc. would not fit in the heading and has been

moved to the footnotes. OK? Please note, this table might be too large to fit in the 2-page layout.

If you would like to have it in the article rather than as supplementary information, please edit it

to be as small as possible.]

\begin{tabular}{|c|c|c|c|}
\hline $\begin{array}{l}\text { Source of } \\
\text { samples } \\
\text { [Au:OK?] }\end{array}$ & $\begin{array}{l}\text { Description of study [Au: The } \\
\text { descriptions have been edited for } \\
\text { brevity. Please ensure new } \\
\text { descriptions are OK] }\end{array}$ & $\begin{array}{l}\text { Cancer } \\
\text { type }\end{array}$ & Tissues collected \\
\hline ARISTOTLE & $\begin{array}{l}\text { Phase III trial of standard concurrent } \\
\text { capecitabine-based NACRT } \pm \\
\text { irinotecan }\end{array}$ & Rectal & $\begin{array}{l}\text { Tumour tissue from diagnostic biopsy; } \\
\text { surgical tumour and nonmalignant mucosal } \\
\text { tissues from tumour resection; plasma for } \\
\text { ctDNA }^{3} \text {; buffy coat for germline DNA }\end{array}$ \\
\hline $\mathrm{CHHiP}$ & $\begin{array}{l}\text { Phase III non-inferiority trial of } \\
\text { conventional IMRT vs two different } \\
\text { hypofractionated schedules of IMRT }\end{array}$ & Prostate & $\begin{array}{l}\text { Prostate cancer [Au: Meaning biopsy or } \\
\text { resection specimens and pre or post } \\
\text { treatment?] }\end{array}$ \\
\hline HALT & $\begin{array}{l}\text { Phase II/III trial of SBRT for } \\
\text { oligoprogressive disease at } \leq 3 \text { sites } \\
\text { after an initial response to standard } \\
\text { TKI therapies }\end{array}$ & NSCLC & $\begin{array}{l}\text { NSCLC [Au: Meaning biopsy or resection } \\
\text { specimens and pre or post treatment?] }\end{array}$ \\
\hline IDRIS & $\begin{array}{l}\text { Phase III trial of standard RT } \pm \\
\text { adjuvant lenalidomide and } \\
\text { dexamethasone for solitary bone } \\
\text { plasmacytoma }^{7}\end{array}$ & $\begin{array}{l}\text { Bone } \\
\text { plasmacyt } \\
\text { oma }\end{array}$ & $\begin{array}{l}\text { Plasmacytoma [Au: biopsy or resection } \\
\text { specimens and pre or post treatment?] }\end{array}$ \\
\hline $\begin{array}{l}\text { IMPORT } \\
\text { HIGH }\end{array}$ & $\begin{array}{l}\text { Phase III trial of dose-escalated } \\
\text { simultaneous integrated boost vs } \\
\text { sequential boost IMRT following } \\
\text { breast-conserving surgery }\end{array}$ & Breast & Blood \\
\hline OCTO $^{9}$ & $\begin{array}{l}\text { Several trials assessing various } \\
\text { interventions }\end{array}$ & Several & $\begin{array}{l}\text { Existing samples of oesophageal, ovarian } \\
\text { and pancreatic cancers and Barrett } \\
\text { oesophagus [Au: By existing samples, do } \\
\text { you mean diagnostic or resection } \\
\text { specimens?] }\end{array}$ \\
\hline PLATO $^{11}$ & $\begin{array}{l}\text { Platform study to optimize RT doses } \\
\text { across disease stages }\end{array}$ & Anal & $\begin{array}{l}\text { Tumour tissue from diagnostic biopsy; } \\
\text { plasma for ctDNA }\end{array}$ \\
\hline PORT & $\begin{array}{l}\text { Phase II trial of pembrolizumab and } \\
\text { RT }\end{array}$ & CTCL & $\begin{array}{l}\text { Skin biopsy samples [Au: pre and/or post } \\
\text { treatment?] }\end{array}$ \\
\hline RAPPER & $\begin{array}{l}\text { Radiogenomics study of } \\
\text { associations between common } \\
\text { SNPs and toxicities from RT }\end{array}$ & Several & $\begin{array}{l}\text { Lung, cervical, prostate and breast cancer } \\
\text { specimens [Au: biopsy or resection } \\
\text { specimens and pre or post treatment?] }\end{array}$ \\
\hline REQUITE & $\begin{array}{l}\text { Observational study to identify } \\
\text { predictors of RT toxicities }\end{array}$ & $\begin{array}{l}\text { Breast, } \\
\text { lung or } \\
\text { prostate }\end{array}$ & $\begin{array}{l}\text { Tumour specimens [Au: OK? Please } \\
\text { provide a little more detail, for example, } \\
\text { on biopsy or resection specimens and pre } \\
\text { or post treatment? I believe blood } \\
\text { samples were also taken?] }\end{array}$ \\
\hline STAR-TREC & $\begin{array}{l}\text { Phase II trial of standard surgery vs } \\
\text { organ-preserving long-course CRT } \\
\text { or short-course RT }\end{array}$ & Rectal & $\begin{array}{l}\text { ctDNA at randomization and therapy; } \mathrm{FFPE}^{16} \\
\text { tissue biopsy specimens and subsequent } \\
\text { surgical specimens [Au:OK?] }\end{array}$ \\
\hline $\begin{array}{l}\text { CRUK-2004- } \\
001621-16 \\
\text { [Au:OK?] }\end{array}$ & $\begin{array}{l}\text { Phase III trial of rituximab vs a } \\
\text { watch and wait approach }\end{array}$ & $\begin{array}{l}\text { Follicular } \\
\text { lymphoma }\end{array}$ & $\begin{array}{l}\text { FFPE tumour specimens or unstained slides } \\
\text { (of lymph nodes or bone marrow); blood and } \\
\text { bone marrow sample at baseline (and post } \\
\text { treatment for patients with CR) }\end{array}$ \\
\hline
\end{tabular}

The table lists tissue collections that have been registered, accessed or approved on the UK Clinical Research Collaboration Tissue Directory and Coordination Centre. CR, complete remission; CRT, chemoradiotherapy; CTCL, cutaneous T cell lymphoma ctDNA, circulating cell-free tumour DNA; FFPE, formalin-fixed paraffineembedded; IMRT, intensity-modulated radiotherapy; NACRT, neoadjuvant chemoradiotherapy; OCTO, Oxford Clinical Trials Office; RT, radiotherapy; SBRT, stereotactic body radiotherapy; SNPs, single-nucleotide polymorphisms; TKI, tyrosine kinase inhibitor. 